\title{
Sternal Variation: Anatomical-Forensic Analysis
}

\begin{abstract}
Viviane Moura Leite ${ }^{1}$ Caroline Freitas de Souza Plácido" Carolina Lucena Veloso Gusmão', Evelyne Pessoa Soriano², Adriana Conrado Almeida², Antonio Azoubel Antines², Gabriela Granja Porto Petraki
\end{abstract}

\section{Abstract}

Background: The aim of this study was to analyze the extent and uniqueness of anatomical variations of the sternum bone, to assess its applicability for forensic analysis, especially for individual human identification.

Methods and Findings: Evaluations involved 501 computer tomography scans performed at the Medical Radiology Center, Manaus city, Amazonas, Brazil, and 427 skeletons belonging to the Collection of Identified Human Skeletons of the Center for Studies in Forensic Anthropology (CEAF), of the University of Pernambuco (UPE), Pernambuco, Brazil. Forms of morphological variations were evaluated, including the presence of foramina, fissures, and incomplete total or partial fusions, as well as forms of xiphoid process termination, and the presence of surgical sutures. Overall, summing computed tomographic images and skeletons, the sternal foramen was present in some $23 \%$ of samples, with a greater proportion in males (14\%), while in females the frequency was $8.6 \%$.

Conclusions: The qualitative analysis of the sternum bone is simple to apply and represents an important potential source of information in a human identification process.
1 Master Forensic Ciences, Faculty of Odontology, Sciences, PE, Brazil.

2 Associate Professor Master Forensic Sciences, PE, Brazil.

Contact information:

Gabriela Granja Porto Petraki.

Address: Av. Governador Agamenon Magalhães s/n, Santo Amaro. Recife, Pernambuco, Brazil. CEP. 50100-010. Tel: +5581992323241.

झ gabriela.porto@upe.br

\section{Keywords}

Sternum; Xiphoid Process; Congenital Anomaly; Computed Tomography; Human Identification. 


\section{Introduction}

During investigations, materials that facilitate identification, such as of dental records, radiographs and medical-dental documents are frequently absent. However, the use of digital medical records is being increasingly adopted by institutions as, in addition to medical history, image examinations performed by the patient are archived. Since it is also common for patients to keep these exams at home throughout their lives, it becomes of paramount importance that such material is requested by experts in those cases involving human identification.

Principally due to the proximity to thoracic organs, such as the heart and lungs, medical recordswill generally indicate if the sternum of a living individuals is fractured or has a foramen, due to the importance of recording such data. This is because in cases of cardiopulmonary resuscitation, fractures in the sternum may occur. These, or existing foramina, may cause or serious cardiac injuries and even death in situations of spinal cord biopsy or acupuncture, due to the proximity of the sternal foramen to the heart $[1,2]$.

It is not always possible, when identifying a body, to apply the primary methods of papilloscopy, dentistry and DNA analyzes, although medical-dental information can be successfully gained ante mortem [3]. However, digital record keeping has been increasingly adopted by medical institutions. In addition to the medical history, this frequently includes any image-based examination performed on the patient. As a result, the analysis of the sternum becomes an option.

Sternum bone formation occurs through the longitudinal fusion of the mesenchyme located on both sides of the chest wall. The mesenchymal bands have their origin in the of the latero-dorsalregion of the body wall and merge in the central zone. These bands appear in the $6^{\text {th }}$ week of intrauterine life. Mesenchymal condensations (or sternal plaques) undergo chondrification and fuse in the midline, in the craniocaudal direction, forming a cartilaginous sternum. Fusion progresses until the $10^{\text {th }}$ week of intrauterine life. Ossification of the cartilaginous sternum then occurs via ossification centers, during the fifth and sixth months of intrauterine life $[5,6,7]$.

Anatomically, the sternum bone is divided into three parts, manubrium, mesosternum (or body) and the xiphoid process [8]. Calcification of the manubrium, usually begins before birth [9]. The process involves calcification centers termed sternebras. There are usually 4 sternebra. Their fusion begins during the third and fourth year of post-natal life, and is completed during adolescence, generally around 12 years old, although it may extend to 25 years $[1,10]$. Sternum development may continue until the third or fourth decade of life [11]. Throughout this process, several anomalies may occur, for example, the bands of the mesenchyme may not join completely along the midline, leaving spaces, so creating sternal fissures $[4,1,12]$.

Post-birth defects may occur during the calcification process between the ossification centers in the manubrium. Here, incomplete fusion of a pair of adjacent sternebra will give rise to the sternal foramina. These can be single or multiple, and are usually located in the lower portion of the mesosternum $[4,13,6,7]$, while incomplete fusion of the lower end of the sternum result in a biphid or perforated xiphoid process $[14,15]$. As a result, the sternum is one of the parts of the skeleton with the highest frequency of anatomical variation $[1,16]$.

The types and frequency of sternum bone anatomical variation have been studied fora variety of locations and populations. These provide an idea of the frequency status of each sternal variation, that is, if the observed characteristic is, as classified by Verna et al (2014): very rare $(<1 \%)$, rare $(1$ to $10 \%$ ), infrequent (10 to $20 \%$ ), frequent (20 to $50 \%$ ) orvery frequent (>50\%). Table 1 summarizes studies to show the types and frequencies of sternal foramina [17]. 
Table 1. Styudies of types of sternam foramina and their frequencies in a variety of human populations.

\begin{tabular}{|c|c|c|c|c|c|}
\hline \multirow{2}{*}{ Authors } & \multirow{2}{*}{ Year } & \multirow{2}{*}{ Population } & \multirow{2}{*}{ Sample type } & \multirow{2}{*}{$\begin{array}{l}\text { Sample } \\
\text { size }\end{array}$} & Prevalence of sternal foramina \\
\hline & & & & & $\%$ \\
\hline Akin & 2011 & Turks & TCMD & 500 & 9 \\
\hline \multirow{2}{*}{ Ashley } & \multirow{2}{*}{1956} & East Africans & \multirow{2}{*}{ Skeletons } & 98 & 13.3 \\
\hline & & Europeans & & 573 & 4 \\
\hline Bayaroğullari & 2014 & Turks & MDCT & 250 & 6 \\
\hline El-Busaid & 2012 & Kenyans & Skeletons & 80 & 13.8 \\
\hline $\begin{array}{l}\text { Macaluso } \\
\text { Lucena }\end{array}$ & 2014 & Spanish & $\begin{array}{l}\text { Cadavers/ } \\
\text { Radiography }\end{array}$ & 122 & 3.3 \\
\hline \multirow{2}{*}{ Mccormick } & \multirow{2}{*}{1981} & \multirow{2}{*}{ USA } & East Africans & \multirow{2}{*}{324} & \multirow{2}{*}{7.7} \\
\hline & & & Europeans & & \\
\hline Paraskevas & 2015 & Greeks & Skeletons & 60 & 18.3 \\
\hline Stark & 1985 & USA & TC & 140 & 4.3 \\
\hline Yekeler & 2006 & Turks & $\mathrm{MDCT}$ & 1000 & 4.5 \\
\hline
\end{tabular}

As can be seen, sternal foramen frequency variad greatly between different studies and populations. This amplitude is the result of research with samples of radiological analysis such as radiographic or computed tomography (CT) or multiple detector computed tomography (MDCT), or examination of cadaveric or anatomical (skeletal) samples.

Accordingly, the current study aimed to analyze the nature and extent of anatomical variations of the sternum bone using computorized tomographic images of the chest as well as morphological analysis of identified human skeletons, to discover to what extent such variation characteristics can be used as a source of information for individualizing human identification.

\section{Methods}

The present study had two phases of data collection. The firstinvolved the analysis of the osteological collection composed of 427 identified human skeletons, belonging to the Pernambuco University Center for Studies in Forensic Anthropology (CEAF), Pernambuco, Brazil. This collec- tion contains individuals from northeastern Brazil, who were buried and exhumed between 2011 and 2018, in the city of Recife, Pernambuco. The individuals represent the current population of the northeast region of Brazil. The research was approved by the Research Ethics Committee of Oswaldo Cruz University Hospital of Pernambuco University (CEP/UPE), under permit no. 3.851.016, CAAE 29279120.6.0000.5192.

Skeletons of both sexes and of any age group, which had a sternum suitable for analysis, were included in the study. Of the 427 human skeletons documented in the collection, 195 had a sternum (45.67\%).

In the second phase of the study, 501 chest CT scans of individuals of both sexes (228 men and 273 women), were analyzed at the Centre for Medical Radiology, in the city of Manaus, Amazonas, located in northern Brazil. The individuals represented the current population of the Northern region of Brazil. The research was approved by the Research Ethics Committee of Pernambuco University (CEP/UPE), under permit n. 2.284.094, CAAE 72907917.8.0000.5207. 
For the tomographic images, individuals of both sexes and of all age groups were included. Presence of a congenital anomaly did not exclude the skeleton or tomographic image from the study, since such items can serve as individualizing characteristics. Tomographic sample participants were not exposed to unnecessary radiation and did not receive medication, because all selected patients had undergone a mandatory chest examination for other reasons and their recordsformed part of the clinic's digital archive.

Data were recorded on a spreadsheet detailing the presence or absence of any variable considered important for inclusion in the current study. Throughout the collection phase, data were reviewed for omissions and corrected.

The variables of discriminating interest considered in the current study were:

1. Manubrial fissure

2. Manubrial foramen

3. Mesosternal fissure

4. Mesosternal foramen

5. Xiphoid Process foramina, single or multiple.

6. Xiphoid Process Terminus, single, bifid or trifid.

7. Presence of Surgical Suture

Statistical tests were performed using the program Statistical Package for Social Science (SPSS ${ }^{\circledR}$ Professional Statistics, version 22.0).

To characterize the studied sample descriptive analysis was carried out to assess variable distribution frequencies. Data analysis calculated absolute and percentage distributions and mean, median and standard deviation (descriptive statistics techniques).

Table 2. Sternal Foramen Frequency.

\begin{tabular}{|c|c|c|c|c|c|c|}
\hline \multirow{2}{*}{ Sample } & MDCT + Skeleton & $n=696$ & MDCT & $n=501$ & Skeleton & $n=195$ \\
\hline & Frequency & $\%$ & Frequency & $\%$ & Frequency & $\%$ \\
\hline Female & 60 & 8.60 & 56 & 11.18 & 4 & 2.05 \\
\hline Male & 101 & 14.53 & 85 & 16.97 & 16 & 8.20 \\
\hline Female + Male & 161 & 23.13 & 141 & 28.15 & 20 & 10.20 \\
\hline
\end{tabular}

\section{Results}

501 computed tomography scans with multiple detectors (MDCT) were analyzed, 55.5\% ( $n=278$ ) of which were female. Of the 195 CEAF skeletons that had the sternum, 58.5\% ( $n=114)$ were from males, and $41.5 \%$ from females. Mean sample age (MDCT and skeletons combined, $\mathrm{n}=696$ ) was 55 years, with a minimum age of 7 and a maximum of 109 years. Median ( $n=696$ ) was 55 years, the mode, 68 years and standard deviation, \pm 17.80 .

In the total sample (MDCT and skeletons), the occurrence of the sternal foramen was $23 \%$, with a greater predilection for males, 14\%, while in females the frequency was $8.6 \%$ (Table 2).

In the MDCT sample, overall sternal foramen occurrance was $28.15 \%$. However, as for mesosternal foramen presence, a percentage difference existed between the sexes, $16.97 \%$ among malesvs $11 \%$ among females (Table 2).

A mesosternal foramen (that is the foramen located in the mid-part of the sternum), was present in $7.33 \%$ of the total sample (MDCT and skeletons). When the samples were seperated, the frequency of the mesosternal foramen was higher in skeletons $(8.72 \%)$, compared to the pure MDCT sample (Table 3).

Among the skeletons, there was single record of a sternal fissure accompanied by foramen in the final third of the mesosternum.

No manubrial fissures were found in either sample. Only one case of foramen was observed on a CT scan of a female patient.

In the MDCT sample, $52 \%$ of the individuals had a xiphoid process with single terminus. It was bifid 
Table 3. Sternal foramen variation frequencies.

\begin{tabular}{|l|c|c|c|c|c|c|}
\hline \multicolumn{1}{|c|}{ Sample } & MDCT + Skeleton & $\mathbf{n = 6 9 6}$ & MDCT & $\mathbf{n = 5 0 1}$ & Skeleton & $\mathbf{n = 1 9 5}$ \\
\cline { 2 - 7 } & Frequency & $\%$ & Frequency & $\%$ & Frequency & $\%$ \\
\hline Manubrial Foramen & 1 & 0.14 & 1 & 0.20 & 0 & 0.00 \\
\hline Sternal fissure & 2 & 0.29 & 1 & 0.20 & 1 & 0.51 \\
\hline Mesosternal Foramen & 51 & 7.33 & 34 & 6.78 & 17 & 8.72 \\
\hline Xiphoid Foramen & 115 & 16.52 & 111 & 22.16 & 4 & 2.05 \\
\hline
\end{tabular}

MDCT: Multiple Detector Computorized Tomography.

Table 4. Frequency of variations of the xiphoid process in the MDCT sample.

\begin{tabular}{|l|c|c|c|c|c|c|}
\multirow{2}{*}{ Sample } & \multicolumn{2}{|c|}{$(\mathbf{n}=\mathbf{5 0 1})$} & \multicolumn{2}{c|}{ Fem. $(\mathbf{n = 2 7 8 )}$} & \multicolumn{2}{c|}{ Male $(\mathbf{n}=\mathbf{2 2 3})$} \\
\cline { 2 - 8 } & Frequency & \& & Frequency & \& & Frequency & \& \\
\hline Single Termination & 261 & 52.09 & 146 & 52.52 & 115 & 51.57 \\
\hline Single Termination (elongated) & 109 & 21.75 & 57 & 20.50 & 52 & 23.32 \\
\hline Bífid Termination & 45 & 9.00 & 27 & 9.71 & 18 & 8.07 \\
\hline Trifid Termination & 20 & 4.00 & 6 & 2.16 & 14 & 6.28 \\
\hline Undefined Termination & 66 & 13.17 & 42 & 15.11 & 24 & 10.76 \\
\hline With Single Foramen & 79 & 15.76 & 31 & 11.15 & 48 & 21.52 \\
\hline With Multiple Foramina & 32 & 6.39 & 8 & 2.88 & 24 & 10.76 \\
\hline
\end{tabular}

in $9 \%$, trifid in $4 \%$ and undefined in $13 \%$. A foramen was present in $27 \%$ of the xiphoid process examined, 15\% being single and 6\% multiple (Table 4). A surgical sternal suture was observed in $1.6 \%(n=8)$ of tomographic images and in $2 \%(n$ $=4$ ) of skeletons.

\section{Discussion}

The first written evidence for sternal foramina occurs in the XVI and XVII centuries, when anatomists of the period, among them Coiter in 1573 and Eustachius in 1714, noted their existance as an important variation $[4,19]$. They were considered most common in the lower third of the mesosternum (Figure 1). In autopsies, sternal foraminawere oberved and decribed as a character of potential forensic value [15] as a characteristic allowing individual indentification. Sternal foraminaare assymptomatic and are occasionally encountered in
Figure 1: Illustrations of the Sternum and its anatomical divisions.

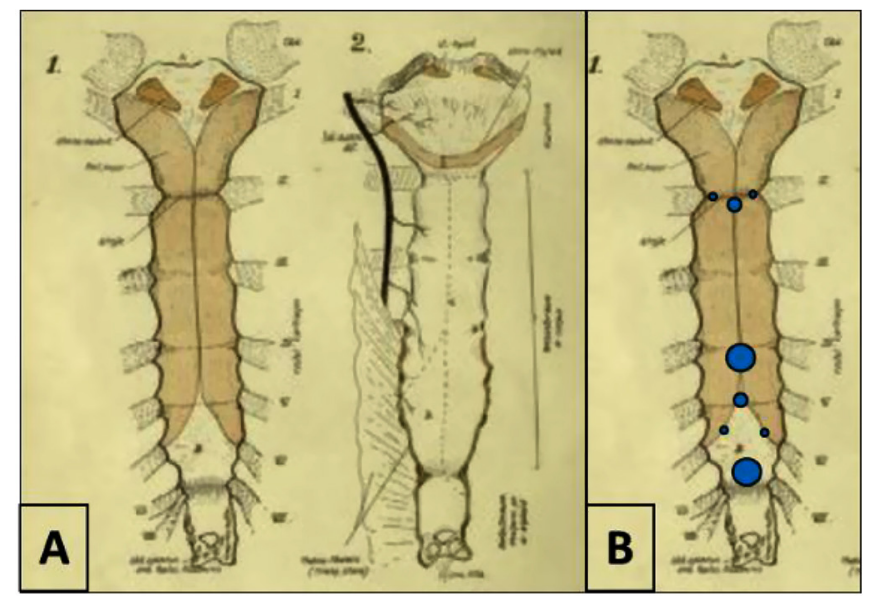

A: (Breathnach, 1958); B: Indications of the antomical locations of sternal fissuress and foramina.

radiographic examinations, such as $\mathrm{CT}$, or inpostmortem analysis (Figure 2) [20, 21, 16]. In MDCT, in axial sections, they appear "bow-tie" formations [16]. Studies under taken in a range of populations 
Figure 2: Sternal foramen.

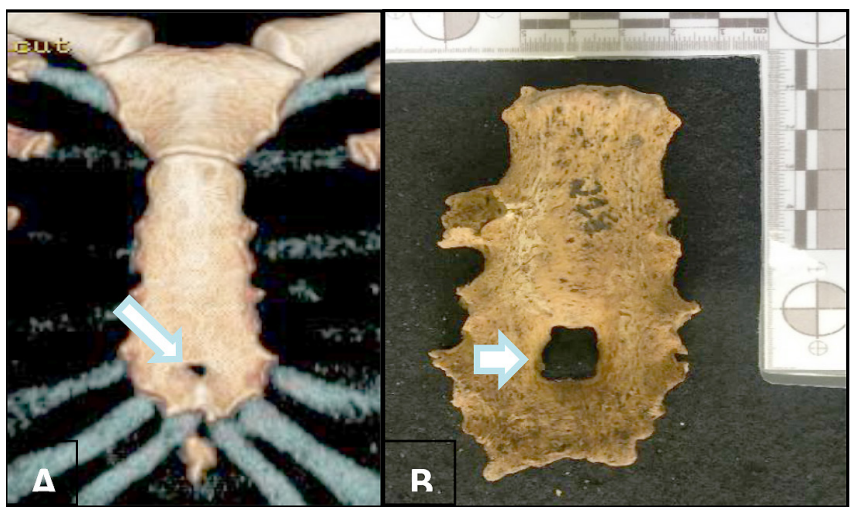

A: CT image, female, 35 years; presence of a foramen; B: skeleton, male, 64 years, formen present.

Figure 3: Manubrial Foramen. Image, Female, 30 years, with a Manubrial Foramen.

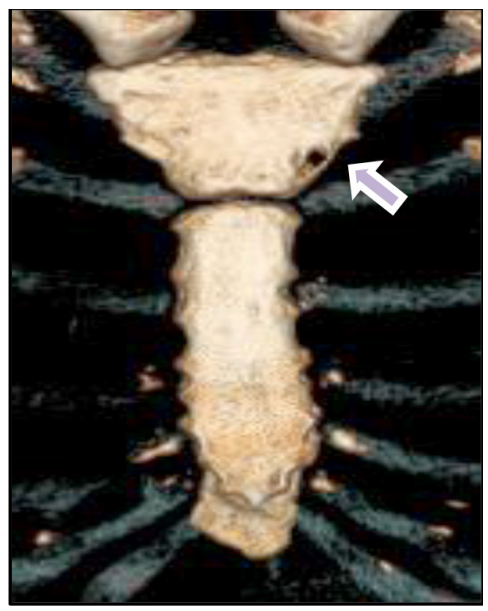

Figure 4: Sternal Fissures. Foramen present in seta 1 and seta 2 .

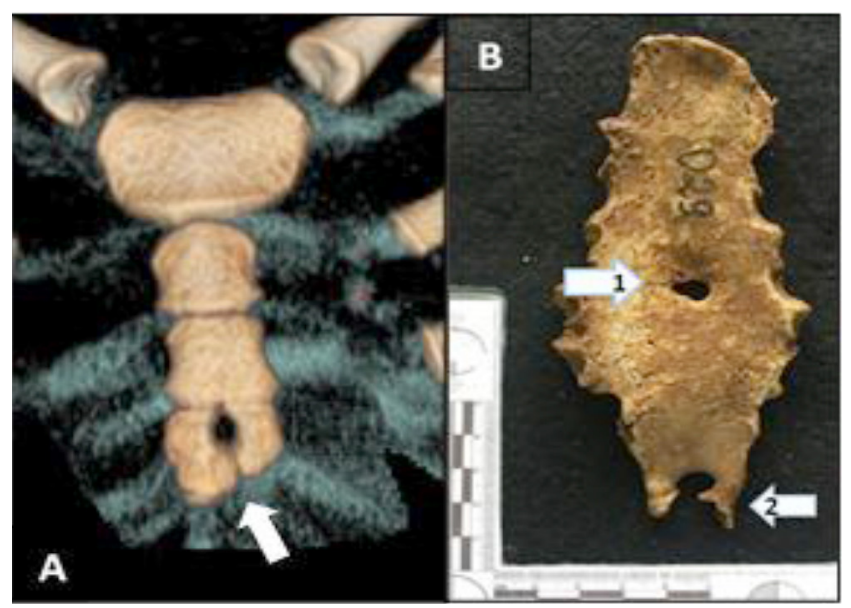

A: CT Image, 12 years, male. Foramen formation. B: skeletal material, male, 29 years, closurehole material. have encountered occurrence frequencies ranging from $12.9 \%$ to $18.3 \%$ for skeletal material [4, 2 , $22,19,23,20$ ] and $3.35 \%$ to $16.65 \%$ inradiological studies $[14,2,9,1,24,25,26,27,15,28,16]$. In the current study the sternal foramen frequency varied by sample $(28.15 \%$ for MDCT; $10.2 \%$ in skeletons).

The manubrial ossification centres unite before birth. Although rare, it is possible for the centres not to fuse, causing a hole in the centre of the manubrium, either incomplete or incomplete [5]. Bayaroğulları et al (2014) recorded the occurance of only one case of incomplete manubrial ossification, and one occurance of a manubrial foramen. In the same study, the authors found no evidence for between-sex difference in the growth and differentiation of themanubrium, and concludedthat manubrial growth was the same in both sexes [1]. In thecurrent study, a MDCT image was recorded of a manubrial foramen $(0.2 \%$ of the MDCT sample, see Figure 3).Therefore, the presence of fissured and foramina in the manubrium is an important finding for imdividual differentiation.

A MDCT image and a skeleton each had a sternal foramen with a slit in the final portion of the mesosterma in the form of a "key hole", similar to cases reported by other authors [16, 12, 20]. The sternal fissumay show complete or incomplete shapes, depending on the extent of fusion failure $[6,16]$. Fusion failure is a rare birth defect. When incomplete forming a foramen, it often has the form of a "keyhole" (Figure 4: [20, 12, 16]). Bayaroğulları et al (2014) evaluated tomographic images of 200 patients between 0 and 20 years old and recorded 15 cases $(7.5 \%)$ of foramina in the manubrium, and 10 cases (5\%) of a sternal fissure [1]. Because this variation has low frequency, it has the potential to be a highly individualspecific character.

Table 5 shows the absolute and percentage values for sternal variations, from other studies in the literature. 
Table 5. Studies of stern foramen frequency.

\begin{tabular}{|c|c|c|c|c|c|c|c|c|}
\hline \multirow[t]{2}{*}{ Authors } & \multirow[t]{2}{*}{ Year } & \multirow[t]{2}{*}{$\begin{array}{c}\text { Type } \\
\text { of sample } \\
\text { studied }\end{array}$} & \multirow[t]{2}{*}{$\begin{array}{l}\text { Sample } \\
\text { Size }\end{array}$} & $\begin{array}{c}\text { Sternal } \\
\text { foramen } \\
\text { prevalence } \\
\text { in sample }\end{array}$ & $\begin{array}{l}\text { Proportion } \\
\text { male: } \\
\text { female }\end{array}$ & $\begin{array}{l}\text { Sternal } \\
\text { Fissure }\end{array}$ & $\begin{array}{l}\text { Prevalence } \\
\text { of } \\
\text { Perfurated } \\
\text { Xiphoid } \\
\text { Process }\end{array}$ & \multirow[t]{2}{*}{$\begin{array}{c}\text { Presenca } \\
\text { of } \\
\text { Manubrial } \\
\text { Foramen }\end{array}$} \\
\hline & & & & $\%$ & $\%$ & $\%$ & $\%$ & \\
\hline Akin & 2011 & MDCT & 500 & 9 & - & - & $34.2-9$ & none \\
\hline \multirow{2}{*}{ Ashley } & \multirow{2}{*}{1956} & \multirow{2}{*}{ Skeleton } & 98 & 13.30 & \multirow{2}{*}{-} & \multirow{2}{*}{-} & \multirow{2}{*}{ - } & \multirow{2}{*}{ none } \\
\hline & & & 573 & 4 & & & & \\
\hline \multirow{2}{*}{ Babinski } & \multirow{2}{*}{2012} & $\mathrm{MDCT}$ & \multirow{2}{*}{180} & \multirow{2}{*}{16.60} & \multirow{2}{*}{-} & \multirow{2}{*}{-} & \multirow{2}{*}{ - } & \multirow{2}{*}{ none } \\
\hline & & Skeleton & & & & & & \\
\hline Babinski & 2015 & MDCT & 114 & 10.5 & 58: 42 & - & - & none \\
\hline Bayaroğullari & 2014 & MDCT & 250 & 6 & - & - & - & 1 case \\
\hline Boruah & 2016 & MDCT & 1180 & 11.60 & - & - & - & none \\
\hline El-Busaid & 2012 & Skeleton & 80 & 13.8 & mes & & 2.50 & none \\
\hline Gkantsinikoudis & 2017 & Skeleton & 35 & 14.20 & mes & & 7 & none \\
\hline Gossner & 2013 & MDCT & 352 & 4.50 & $3: 2$ & & & none \\
\hline Kirum & 2017 & Skeleton & 100 & 12.90 & - & 8.20 & 9.50 & none \\
\hline $\begin{array}{l}\text { Macuso } \\
\text { Lucena }\end{array}$ & 2014 & $\begin{array}{l}\text { Cadavers/ } \\
\text { Radiography }\end{array}$ & 122 & 3.3 & Only mes & - & - & none \\
\hline Mccormick & 1981 & $\begin{array}{l}\text { Cadavers/ } \\
\text { X-Rays }\end{array}$ & 324 & 7.7 & - & - & - & none \\
\hline Mccormick & 1981 & Cadavers/ & 324 & 7.7 & - & - & - & none \\
\hline \multirow{2}{*}{ Moore } & \multirow{2}{*}{1988} & \multirow{2}{*}{ Radiography } & \multirow{2}{*}{2016} & \multirow{2}{*}{6.7} & $2: 1$ & \multirow{2}{*}{ - } & \multirow{2}{*}{ - } & \multirow{2}{*}{ none } \\
\hline & & & & & 9.6: 4.3 & & & \\
\hline Paraskevas & 2015 & Skeleton & 60 & 18.3 & - & 2 cases & - & none \\
\hline Stark & 1985 & $\mathrm{TC}$ & 140 & 4.30 & - & - & - & none \\
\hline Turkay & 2017 & MDCT & 544 & 5.20 & - & 0.60 & - & none \\
\hline Yekeler & 2006 & $\mathrm{MDCT}$ & 1000 & 4.5 & - & 1 case & 27.40 & none \\
\hline \multirow{2}{*}{ Currentstudy } & & $\mathrm{MDCT}$ & 501 & \multirow{2}{*}{23.13} & $1: 1$ & \multirow{2}{*}{1 case } & \multirow{2}{*}{11.93} & 1 caco \\
\hline & & Skeleton & 195 & & $3: 1$ & & & I case \\
\hline
\end{tabular}

In the literature consulted, the frequency of sternal foramina in the xiphoid process varied between 2.5\% and 34\% (Table 6, Figure 8). In the current study, the recorded prevalence (15.76\%) lay within the range reported by these other authors. Akin et al. (2011) reported the presence of multiple xiphoid sternal foramina in $9 \%$ of the study population, while in the current study, this situation occured in $6 \%$ of the MDCT sample (Figure 9). The xiphoid process, from the Greek xifhos ("straight sword"), is a region with many morphological variations. At birth, it is cartilaginous. During adulthood, the xiphoid process is ossified, merging into the mesostern in older individuals $[19,16]$. The morphologi- 
Table 6. Survey of literature to show variation in xiphoid terminus morphology.

\begin{tabular}{|c|c|c|c|c|c|c|c|}
\hline \multirow[t]{2}{*}{ Authors } & \multirow[t]{2}{*}{ Year } & \multirow[t]{2}{*}{$\begin{array}{l}\text { Type } \\
\text { of } \\
\text { sample } \\
\text { studied }\end{array}$} & \multirow[t]{2}{*}{$\begin{array}{l}\text { Sample } \\
\text { Size }\end{array}$} & $\begin{array}{l}\text { Prevelance } \\
\text { of } \\
\text { single } \\
\text { xiphoid } \\
\text { terminus }\end{array}$ & $\begin{array}{l}\text { Prevelance } \\
\text { of } \\
\text { bifid } \\
\text { xiphoid } \\
\text { terminus }\end{array}$ & $\begin{array}{l}\text { Prevelance } \\
\text { of } \\
\text { trifid } \\
\text { xiphoid } \\
\text { terminus }\end{array}$ & $\begin{array}{l}\text { Prevelance } \\
\text { of } \\
\text { peeforated } \\
\text { xiphoid } \\
\text { terminus }\end{array}$ \\
\hline & & & & $\%$ & $\%$ & $\%$ & $\%$ \\
\hline Akin & 2011 & MDCT & 500 & 62.6 & 32.8 & $4.6 \%$ & $34.2-9$ \\
\hline Babinski & 2015 & $\mathrm{MDCT}$ & 114 & - & 17.5 & - & - \\
\hline El-Busaid & 2012 & Skeleton & 80 & 80 & 12.5 & & 2.5 \\
\hline Gkantsinikoudis & 2017 & Skeleton & 35 & - & - & - & 7 \\
\hline Kirum & 2017 & Skeleton & 100 & - & 42.9 & - & 9.5 \\
\hline $\begin{array}{l}\text { Macaluso } \\
\text { Lucena }\end{array}$ & 2014 & $\begin{array}{l}\text { Cadavers/ } \\
\text { Radiography }\end{array}$ & 122 & 54.9 & 41.6 & - & - \\
\hline Turkay & 2017 & $\mathrm{MDCT}$ & 544 & 72 & 25 & $1 \%$ & - \\
\hline Yekeler & 2006 & $\mathrm{MDCT}$ & 1000 & 71 & 27.2 & 0.7 & 27.4 \\
\hline Currentestudy & & $\mathrm{MDCT}$ & 501 & 52.09 & 9 & $4 \%$ & 15.76 \\
\hline
\end{tabular}

Figure 5: Xiphoid Process-Single Terminus.

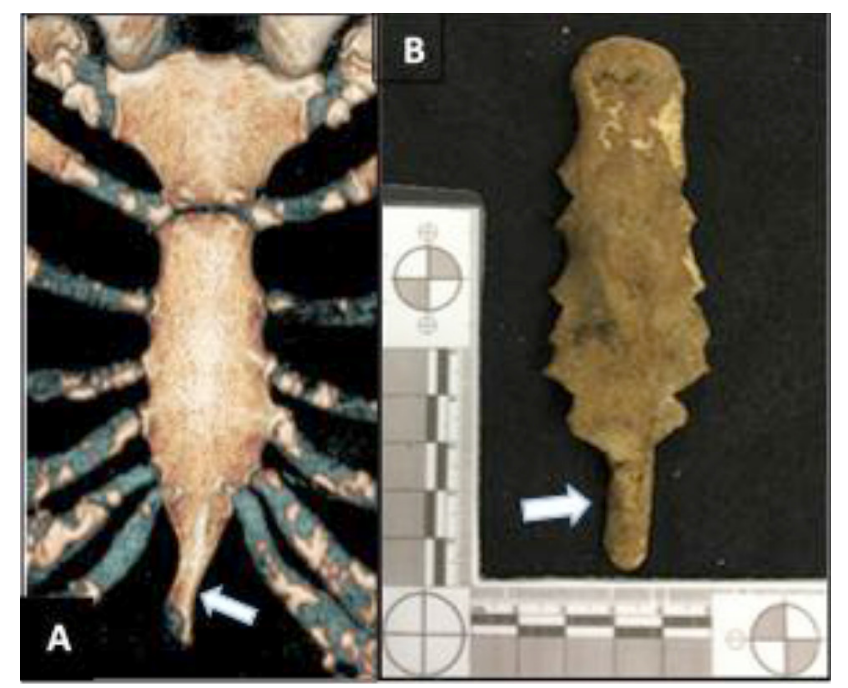

A: CT image, female, 63 years; B: skeletal material, female 25, both with a single terminus to the xiphoid process

cal variations lack any known clinical significance. Yekerlar et al. (2006) described the presence of a tri-partate xiphoid process with associated foramina [16]. In the current study, $52.9 \%$ of the MDCT had a uniform xiphoid process, while in $21 \%$ the terminus was single, but elonated. However, this region allows individuals to be distunguished since it shows significant morphological variation within the various populations studied, as shown in Table 6 and Figure 5.

Another qualitative individualizing aspect observed in the current study was the fusion of the sternal, manubriosternal and sternoxiphoidal joints. These fibrocartilaginous regions will continue to calcify throughout life, until complete fusion, forming a single bone piece (Figure 10) [7, 16]. Sternal articulation calcification can occur in an incompletly, in which case some small areas will remain open forming small unique foramina (Figures $9 \mathrm{C} \& 9 \mathrm{E})$, which are termed pseudoforamina or pseudofissures. These features have no known clinical significance, but canbe important in identifiying individuals. Unless the person is suffering osteodegeneration, manubriosternal articulationis usually complete by 25 years of age $[5,10,16]$, with the sternoxiphoidal complete by 40 years. A studyby Yekerlar et al. (2006) shed that 20 year olds showed complete fusion of the two sternal articulations. Turkay et al. (2017) studied 544 MDCT 
Figure 6: Xiphoid Process-Bifid Terminus.

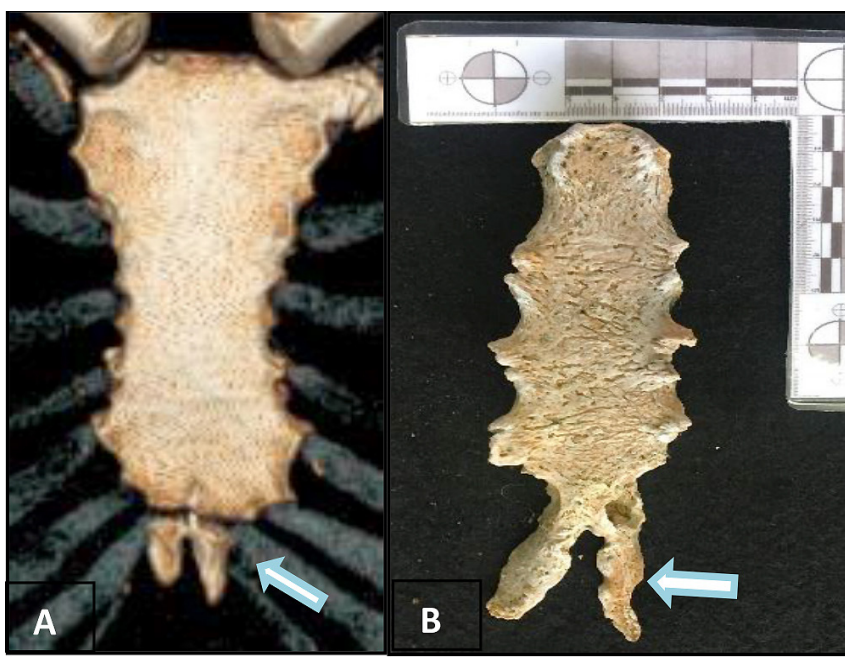

A: CT image, female, 42 years; B: skeletal material, male, 31, both with a bifid terminus to the xiphoid process.

Figure 7: Xiphoid Process-Trifid.

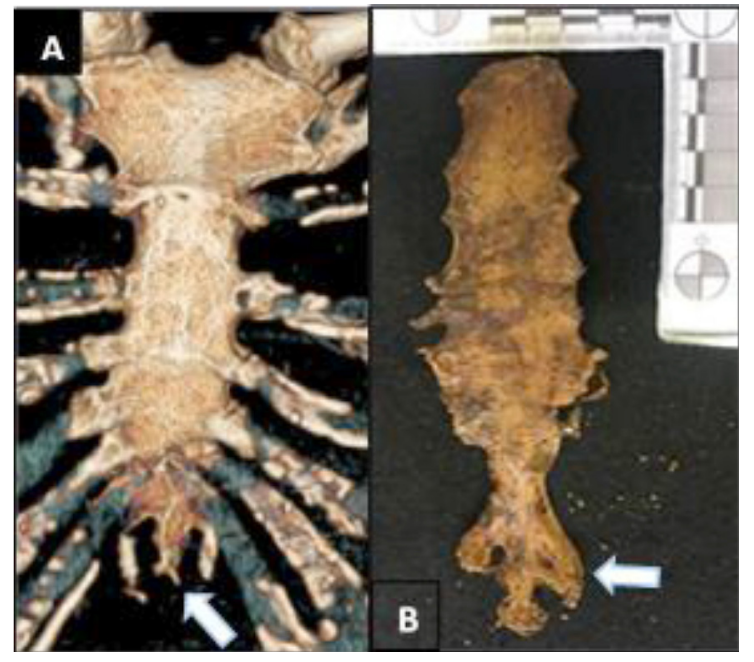

A: CT image, female, 62 years; B: skeletal material, male, 61, both with a trifid terminus tothe xiphoid process.

images from individuals covering an 18 to 95 year age range. In their sample, the youngest patient with complete fusion in all sternal articulations was 32 years old. In the current study, where the sample ranged from 7 to 109 years, als found agerelated differences (Figures $10 \& 11$ ).

Due to their importance in various pathological or preventive situations, once the presence of fissures and/or foramina is diagnosed it is essential
Figure 8: Xiphoid Process-Single. Foramen.

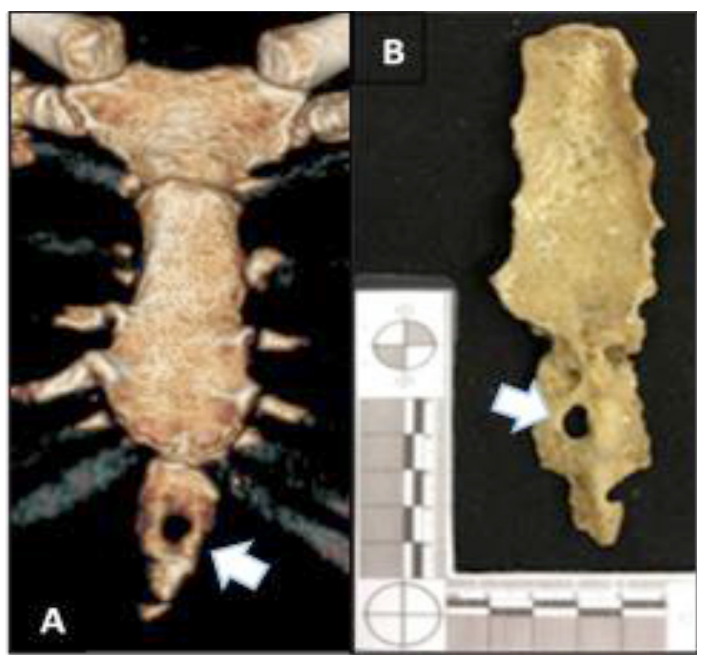

A: CT image, female, 56 years; B: skeletal material, male 49, both with a xiphoidal foramen.

that such information be recorded in the medical record of a patient. Information on the presence of sternal fissures and foramina must be available to the health team in cases, for example, of cardiopulmonary resuscitation, sternal biopsy procedure, bone marrow aspiration, acupuncture practice, and also to avoid diagnostic errors in cases of patients with complaints of chest pain, victims of accidents or physical aggression, where they might be confused with fractures of the sternum [10, 1, 29, 30, 31]. Fatal cases of heart penetration have been documented in the literature, for example, Babinski et al. (2012) analyzed 16 bodies with sternal foramina, and all of had damage to the right ventricle of the heart caused by transthoracic penetration of needles, due to the existence of a sternal foramen in a position that lay above the heart.

Likewise, the lack of knowledge of the morphological variations of the sternum bone can hinder investigations of the cause of death [32]. Erroneous interpretation of sternum bone anatomical variation may hinder forensic investigations if it is mistaken and classified as a firearm projectile injury or other type of traumatic penetration, especially in post mortem examinations of bodies in an advanced 
Figure 9: Xiphoid Process Foramina. Small foramina: A, B and C, CT image; D and E, skeletal material.

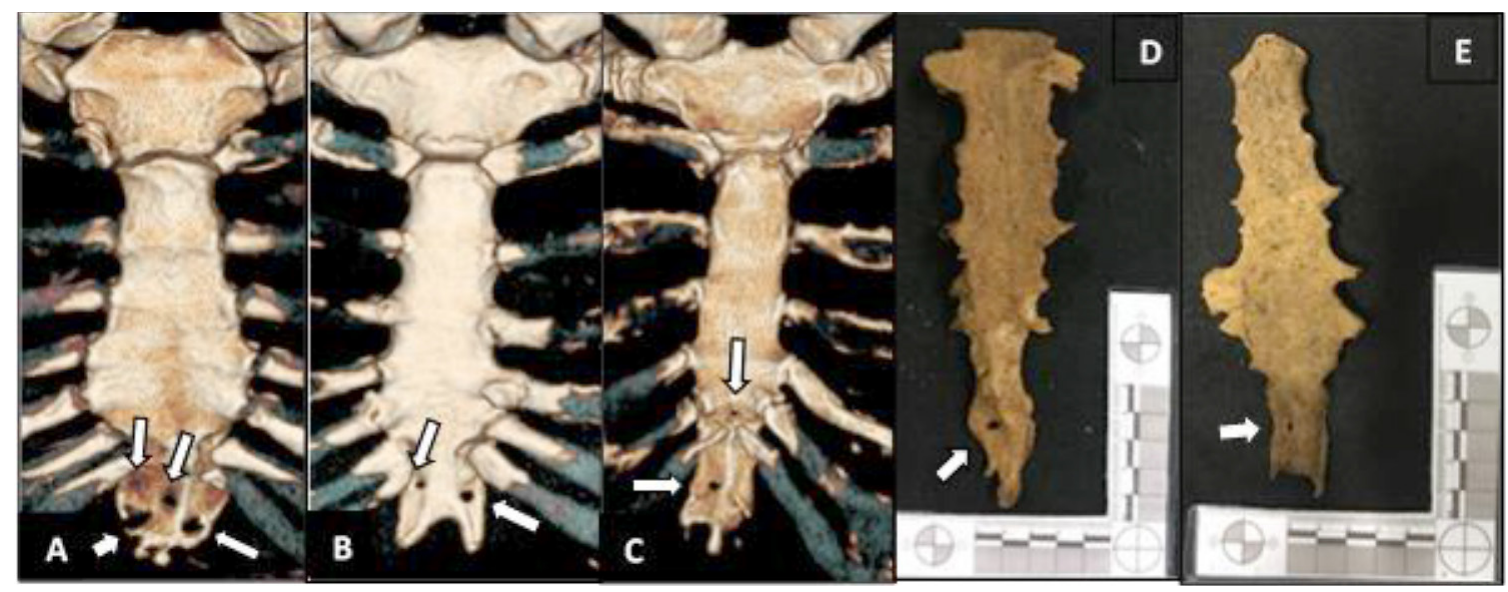

Figure 10: Sternal Articulations.

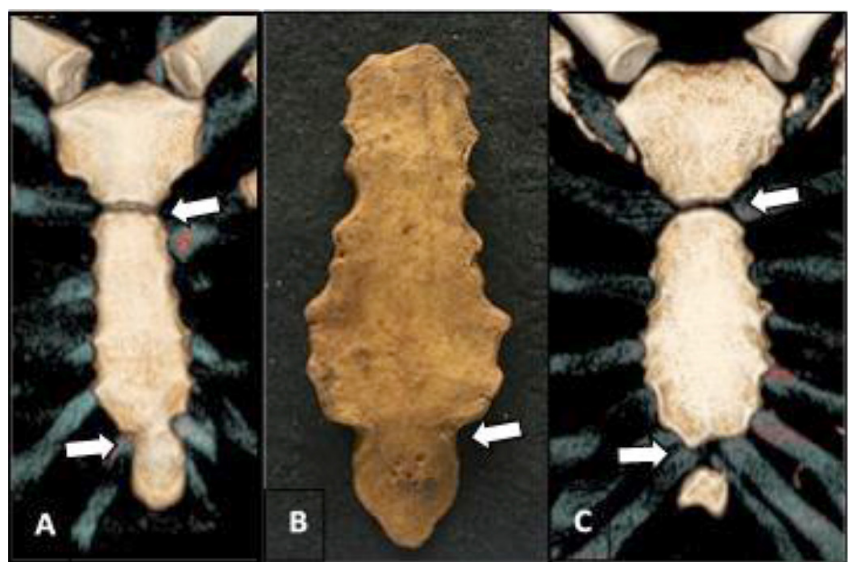

$A: C T$, male, 20 years; in B, image of skeletal material, female, 23 years; C: male, 25 years, showing the sternal articulations in different stages of calcification.

Figure 11: Sternal Articulations-Total. Fusion. Skeletal material, male, 78 years.

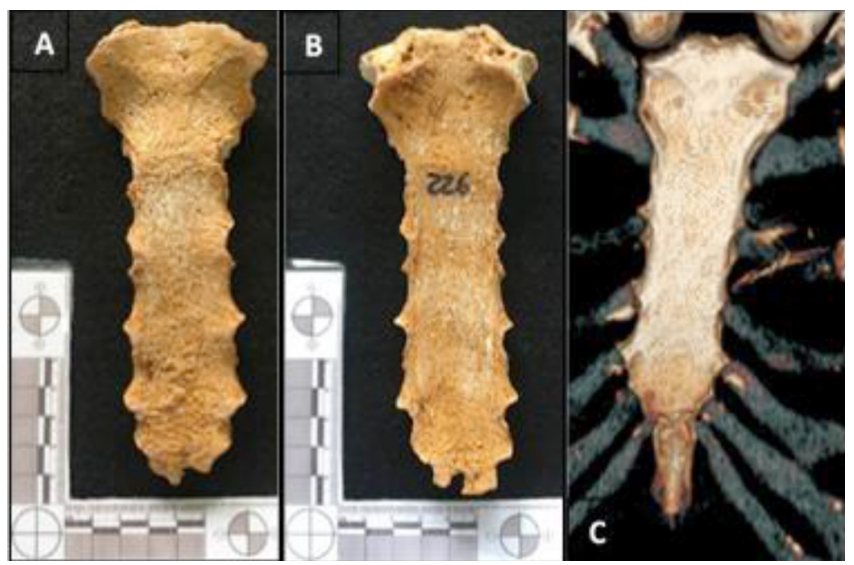

A/B: external and internal faces, showingcomplete fusion of the sternal articulations. C: CT image, male, 60. state of decomposition, so causing error in investigations of causa mortis and, consequently, in the homicide investigations $[26,8]$. In such cases it is important to check medical records for the existance of these forms of variation. Several authors have stressed the importance of such finding for forensic anthropology in cases that would contribute to idenividuak identification of human skeletons [33, $10,32,28]$.

In the current study, the presence of surgical sutures in the sternum was observed, both in MDCT (8 cases) and skeletal (4 cases) samples (a total of $1.72 \%$ of the entire sample, $n=696$ (Figures 12

Figure 12: Surgical Sutures.

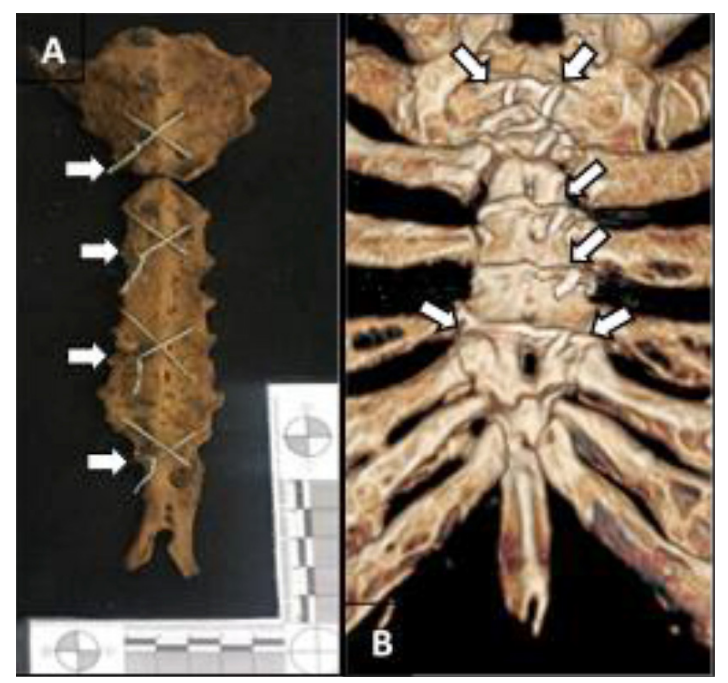

A: skeletal material, male, 58 years; B: CT image, male 69 years, both showing the presence of surgical sutures. 
\& 13). There are no records in the consulted literature regarding the presence of sutures in the reviewed literature because, as noted by Babinski et al (2015), the presence of sutures, deformations and chest trauma are generally excluded from sample reporting. However, in a forensic investigation that aming to identify human bidy, this can be important individualizing information.

Figure 13: Sternal Sutures.

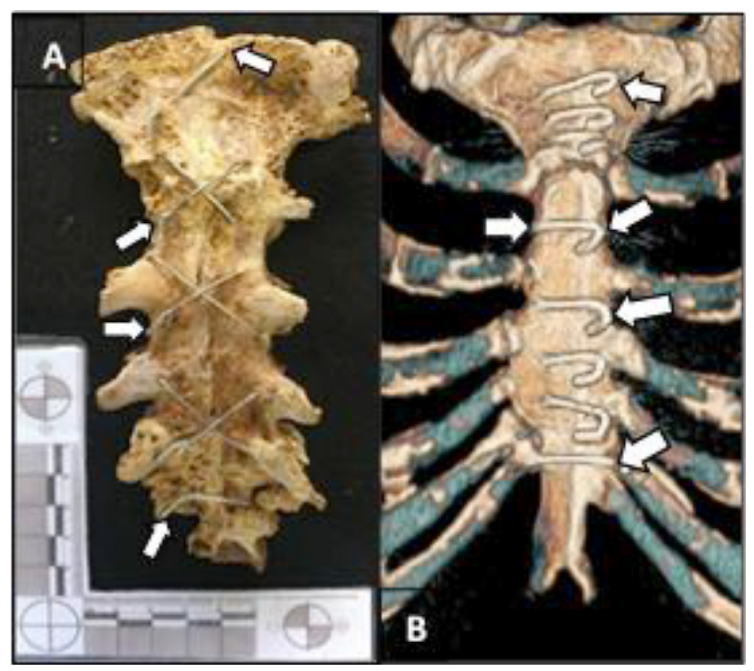

A: skeletal material, female, 90 years; B: CT image, female 70 years, both showing the presence of surgical sutures.

\section{Conclusion}

Qualitative analysis of the sternum is simple to apply and can safely be used to obtain a positive human identification. The presence of surgical sutures, not yet referenced in the literature consulted as an individualizing datum, greatly enhances image comparison reliability since each suture islikley to have a unique form. The absence from medical records of information on a patient having asternal fissure or foramen can result in a variety of fatalities. For this reason, it is recommended that such information be recorded in medical records as soon as it is discovered. This practice will certainly facilitate any eventual post mortem forensic investigation.

\section{References}

1. Bayaroğulları H, Yengil E, Davran R, Ağlagül E, Karazincir $S$, Balcı A. Evaluation of the postnatal development of the sternum and sternal variations using multidetector CT, Diagn Interv Radiol, 201420 (1): 82-89.

2. Babinski MA, Rafael FA, Steil AD, Sousa-Rodrigues CF, Sgrott EA. De Paula RC. High prevalence of sternal foramen: quantitative, anatomical analysis and its clinical implications in acupuncture practice, Int J Morphol, 201230 (3): 1042-1049.

3. Michaud LC, Foran DR. Simplified Field Preservation of Tissues for Subsequent DNA Analyses, J Forensic Sci, 201156 (4): 846-52.

4. Ashley $\mathrm{G}$. The relationship between the pattern of ossification and the definitive shape of the mesosternum in man, J Anat., 195690 (1): 87-105

5. Duraikannu C, Noronha OV, Sundarrajan P. MDCT evaluation of sternal variations: Pictorial essay, Indian J Radiol Imaging, 2016 26 (2): 185-194.

6. Fokin AA. Cleft sternum and sternal foramen, Chest Surg Clin N Am, 2000 10: 261-276.

7. Goodman LR, Teplick SK, Kay H. Computed tomography of the normal sternum, AJR Am J Roentgenol, 1983 141: 219-223.

8. Budd JS. Effect of seat belt legislation on the incidence of sternal fractures seen in the accident department, Br Med J, 19856498 (291): 785.

9. Babinski MA, Lemos L, Babinski MS. Gonçalves MD. Frequency of sternal foramen evaluated by MDCT: a minor variation of great relevance, Surg Radiol Anat., 201537 (3): 287-291.

10. Stark P, Jaramillo D. CT of the sternum, AJR Am J Roentgenol, 1986 147: 72-7.

11. Moore MK, Stewart JH, McCormick WF. Anomalies of the human chest plate area. Radiographic findings in a large autopsy population, Am J Forensic Med Pathol, 1988 9: 348-54.

12. Saccheri JP, Sabbadini G, Toso F, Travan L. A keyholeshaped sternal defect in an ancient human skeleton, Surg Radiol Anat, 2012 34: 965-968.

13. Breathnach AS. Frazer's Anatomy of the Human Skeleton, 1958. [Internet]. Available from: https://archive.org/details/ anatomyofhumansk00frazuoft/page/n89/mode/2up

14. Akin K, Kosehan D, Topcu A. Anatomic evaluation of the xiphoid process with 64 row multidetector computed tomography, Skeletal Radiol, 2011 40: 44752.

15. Moore KL, Persuaud TVN, Fernandez E. Embriologia Básica., 8 ed., Rio de Janeiro: Editora Elsevier, 2008.

16. Yekeler E, Tunaci M, Tunaci A, Dursun M, Acunas G. Frequency of sternal variations and anomalies evaluated by MDCT, AJR Am J oentgenol, 2006186 (4): 956-960

17. Verna E, Piercecchi-Marti M, Chaum K, Adalian P. "Relevance of discrete traits in forensic anthropology: From the first," Forensic Science International, 2015 253: 134.e1-134.e7.

18. Stark P. Midline sternal loramen: CT demonstration, J Comp Assist Tomogr, 1985 9: 489-490. 
19. Gkantsinikoudis N, Chaniotakis C, Gkasdaris G, Georgiou N, Kapetanakis S. Morphological approach of the sternal foramen: an anatomic study and a short review of the literature, Folia Morphol, 201773 (3): 484-490.

20. Paraskevas G, Tzika M, Anastasopoulos N, Kitsoulis P, Sofidis G, Natsis K, Sternal foramina: incidence in Greek population, anatomy and clinical considerations., Surg Radiol Anat, 201537 (7): 845-851.

21. Paraskevas GK, Tzika M, Natsis K, Double sternal foramina in a dried sternum: a rare normal variant and its radiologic assessment, Surg Radiol Anat., 201638 (8): 991-993.

22. El-Busaid H, Kaisha W, Hassanali J, Hassan S, Ogeng'o J, Mandela P. Sternal foramina and variant xiphoid morphology in a Kenyan population, Folia Morphol (Warsz), 201271 (1): 19-22.

23. Kirum GG, Munabi I, Kukiriza J, Tumusiime G, Kange M, Ibingira C, Buwembo W. Anatomical variations of the sternal angle and anomalies of adult human sterna from the Galloway osteological collection at Makerere University Anatomy Department, Folia Morphol, 2017, 76 (4): 689-694.

24. Boruah DK, Prakash A, Yadav RR, Dhingani DD, Achar $S$, Augustine $A$, et al. The safe zone for blinded sternal interventions based on CT evaluation of midline congenital sternal foramina, Skeletal Radiol, 2016, 45: 1619-1628.

25. Gossner J. Relationship of sternal foramina to vital structures of the chest: a computed tomographic study, Anat Res Int, vol. 2013, 2013

26. Macaluso PJ, Lucena J. Morphological variations of the anterior thoracic skeleton and their forensic significance: adiographic findings in a Spanish autopsy sample, Forensic Sci Int, 2014, 241: 220.e1-220.e7.

27. McCormick WF. Sternal foramena in man, Am J Forensic Med Pathol, 1981, 2 (3): 249-252.

28. Turkay $R$, Inci $E$, Ors $S$, et al. Frequency of sternal variations in living individuals, Surg Radiol Anat, 2017, 39: 1273.

29. Cubuk S, Hamcan S. Anatomic variations of sternum may mimic traumatic complications, Am J Emerg Med, 2016, 2 (34): 1912. e1-1912.e2.
30. Jakhar JK, Dagar T, Dhattarwal SK, Pal V. The Sternal Foramen:The possible Forensic Misinterpretation of an Anatomic Abnormality, J Indian Acad. Forensic Med, 2015, 37 (3): 315-316.

31. Taylor HL. The sternal foramen: the possible forensic misinterpretation of an anatomic abnormality, J Forensic Sci, 1974, 19: 730-734

32. Sebes JI, Salazar JE. The manubriosternal joint in rheumatoid disease, AJR Am J Roentgenol, 1983, 140: 117-21.

33. Tarladacalisira, Karamustafaoglub YA. A rare entity: sternal foramen, Eur J Cardiothorac Surg, 2013, 44: 384.
Publish in International Archives of Medicine

International Archives of Medicine is an open access journal publishing articles encompassing all aspects of medical science and clinical practice. IAM is considered a megajournal with independent sections on all areas of medicine. IAM is a really international journal with authors and board members from all around the world. 